\title{
Numerical Analysis of Thermal Conductivity of Non-Charring Material Ablation Carbon-Carbon and Graphite with Considering Chemical Reaction Effects, Mass Transfer and Surface Heat Transfer
}

\author{
H. Mohammadiun ${ }^{1}$,A. Kianifar $^{2}$, A. Kargar $^{3}$
}

\begin{abstract}
Nowadays, there is little information, concerning the heat shield systems, and this information is not completely reliable to use in so many cases. for example, the precise calculation cannot be done for various materials. In addition, the real scale test has two disadvantages: high cost and low flexibility, and for each case we must perform a new test. Hence, using numerical modeling program that calculates the surface recession rate and interior temperature distribution is necessary. Also, numerical solution of governing equation for non-charring material ablation is presented in order to anticipate the recession rate and the heat response of non-charring heat shields. the governing equation is nonlinear and the NewtonRafson method along with TDMA algorithm is used to solve this nonlinear equation system. Using Newton- Rafson method for solving the governing equation is one of the advantages of the solving method because this method is simple and it can be easily generalized to more difficult problems. The obtained results compared with reliable sources in order to examine the accuracy of compiling code.
\end{abstract}

Keywords - Ablation rate, surface recession, interior temperature distribution, non charring material ablation, Newton Rafson method.

\section{INTRODUCTION}

$\mathrm{D}$ ESIGN, selection, and sizing of a thermal protection system (TPS) and the skin material for reentry vehicles are problems of great importance [1] and one of the greatest challenges in designing aerospace structure is determine the internal thermal field, which is generated by aerodynamic heating during the atmospheric flight phase of a space vehicle [2]. The success of a space mission depends on the correct evaluation of the mechanical and thermal loads on a reentry vehicle during the reentry path into the planet atmosphere. At high Mach numbers, the blunt body generates a bow shock and causes a rather high pressure, which in turn leads to a high aerodynamic drag needed for decelerating or aero braking reentry capsules. Most current aero thermodynamic designs

1. Islamic Azad University-Shahrood Branch

(e-mail: hmohammadiun $@$ yahoo.com )

2. Department of Mechanical Engineering, Ferdowsi University of Mashhad, Iran (e-mail: a_kianifar@yahoo.com).

3. Islamic Azad University -Quchan Branch

(e-mail: ali_kargar_57@yahoo.com) feature a blunt for body, shielding the payload from the intense heat generated during atmospheric reentry. When a launch vehicle cruises at a high Mach number through the atmosphere, the kinetic energy of the fluid transforms to internal energy, which eventually leads to a rise in temperature within the boundary layer. This phenomenon is generally referred to as viscous dissipation. The vehicle surface takes on a very high temperature that even materials with high melting points cannot withstand [1]. This is especially important around the vehicle nose and could destroy the structure. For example, the stagnation point temperature of vessel that arrives to atmosphere at 36 Mach $11000 \mathrm{~K}$ [3]. Obviously, this situation could be tolerated by neither any structure nor any common heat insulation unless the special mechanism has been used to reduce the effects of strong heat flux. Some of these high temperature thermal systems, used in these conditions include heat-sink system, leakage cooling and ablative cooling. Heat sink materials that are the high-heat capacity materials prevent to increase of temperature in the structure with storing the input heat flux. In the leakage cooling, through surface pores, the fluid is injected inside the boundary layer and then the hot boundary layer is removed from the surface. Ablative insulation, considered in this study, performs the phase changes and chemical reaction absorb. Therefore, they absorb and lose some amount of heat flux when exposed to hot gases. In this manner, ablative insulations sacrifice themselves for the main structure and prevent it from damage [4]. The surface temperature of heatsink system materials is also vanished by the ablative system and it prevents the structure overweight. An efficient design of thermo structural protection relies on an accurate evaluation of the wall recession caused by ablation. In particular, $\mathrm{C} / \mathrm{C}$ composites develop surface roughness features, which may display a strong coupling with the surrounding environment [5]. Carbon/Carbon(C/C) composites, which keep excellent mechanical properties at high temperature are used as thermo structural protections in various applications such as atmospheric reentry [6,7]. Historically, the first specific studies on this phenomenon are conducted in late 1960s and early 1970s, based on the first study of Vonkarman [8] 


\section{MATHEMATICAL MODEL}

Generally, in differential equations, some terms are omitted; afterwards, governing equations upon ablative graphite are obtained, so graphite is non-charring. To solve the equation, it is better that the basic site axis basis conforms to the material surface because of the ablative surface recession [9].

As follows, the energy equation is presented:

$\frac{\partial}{\partial z}\left(k(T) \frac{\partial T}{\partial z}\right)+\dot{S} \frac{\partial}{\partial z}(\rho h(T))=\rho C_{p}(T) \frac{\partial T}{\partial t}$

In above relations $\dot{S}$ is calculated by the following proportion:

$$
\dot{S}=\frac{\dot{m}_{a b}}{\rho}
$$

The assumption of chemical equilibrium in the reaction surface of ablative material is accepted as a standard assumption. According to this assumption, an important part of ablation happens in high temperature and high pressure in a way that in these conditions, the reactions are very fast and the chemical equilibrium is dominant. Calculating the chemical equilibrium of the open systems is done with the help of thermodynamic and stoichiometry relations of the reactions. EST and ACE computer codes calculate the ablation rate using the thermodynamic properties of the materials in JANAF tables[10]. In the present study some tables of data are provided from the results of applying EST code and then these data are related to each other as one function. The input to these functions are the surface temperature $\left(\mathrm{T}_{\mathrm{w}}\right)$, the surface pressure $\left(p_{w}=p_{e}\right)$ and the normalized mass flux of pyrolysis gas. The outputs of these functions are in mass flux of surface ablation, and gas enthalpy along the wall, and the mass transfer coefficient is calculated from ablative mass flux.

\section{BOUNDARY CONDITIONS}

Figure 1- schematically shows a model of the ablative material

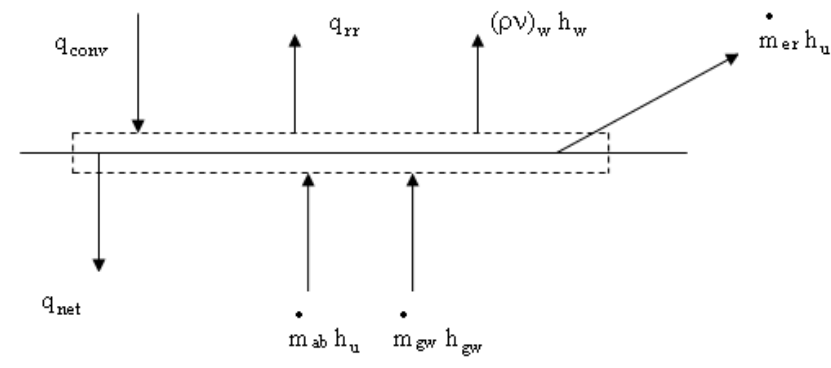

Fig. 1 Schematic drawing of the ablative material

As seen, in addition to heat transfer through convection, radiation and conduction, absorption or heat production, related to chemical reaction, should be modeled. According to figure (1), the input and output energy terms to ablative material surface are:

\begin{tabular}{|l|c|}
\hline$\left.q_{\text {net }}=-k \frac{\partial T}{\partial z}\right)_{w, \text { solid }}$ & Conduction heat flux \\
\hline$\dot{m}_{a b} h_{u}, \dot{m}_{g w} h_{g w}$ & $\begin{array}{c}\text { Input heat flux to surface for } \\
\text { pyrolysis gases and char }\end{array}$ \\
\hline
\end{tabular}

\begin{tabular}{|l|l|}
\hline$\dot{m}_{e r} h_{u}$ & cooling phase \\
\hline$q_{\text {rad , in }}, q_{\text {rad out }}$ & $\begin{array}{l}\text { Input and output of radiation } \\
\text { heat flux }\end{array}$ \\
\hline$(\rho v)_{w} h_{w}$ & $\begin{array}{l}\text { Output flux from surface for } \\
\text { mass flux }(\rho v)_{w} h_{w}\end{array}$ \\
\hline$q_{\text {conv }}$ & $\begin{array}{l}\text { Penetration of energy to gas } \\
\text { phase }\end{array}$ \\
\hline
\end{tabular}

It should be noted that the control volume, as it shown, is constant relative to ablative material. Therefore, conservation of energy equation in material surface is:

$$
\begin{aligned}
\dot{q}_{\text {net }}=\dot{q}_{\text {conv }}-\dot{q}_{r r}-\dot{m}_{a b}( & \left.h_{w}-h_{u}\right) \\
& -\dot{m}_{g w}\left(h_{w}-h_{g w}\right)
\end{aligned}
$$

For carbon- carbon composite $h_{g w}=0$, so the last equation would be changed as follows:

$$
\begin{aligned}
\dot{q}_{\text {net }}=\dot{q}_{c w}\left(1-h_{w} / h_{r}\right) & \phi_{\text {HAL }} \phi_{\text {blow }} \\
& -\varepsilon \sigma\left(T_{w}^{4}-T_{r e f}^{4}\right)-\dot{m}_{a b}\left(h_{w}-h_{u}\right)
\end{aligned}
$$

In the above equation $\dot{q}_{c w}$ is cold wall of heat flux and $h_{r}$ is recovery enthalpy, calculated by aerodynamic relations. $\phi_{\text {blow }}$ Relates to blow, resulted from the gas entering the boundary layer, and it is calculated by the following relation [10]:

$\phi_{\text {Blow }}=\frac{\ln \left(1+a_{1} B^{\prime}\right)}{a_{1} B^{\prime}}$

In the above equation, the amount of $a_{1}$ equals1.5. $\phi_{\text {Hall }} \geq 1$, is the abrasion coefficient and for the state in which there is no abrasion it equals 1 . The emission coefficient, also, equals $0.9 . h_{u}$, is determined as follows [10]:

$$
\begin{aligned}
& h_{u}=\int_{T_{\text {ref }}}^{T_{w}} C_{p} d T= \\
& C_{\infty}\left(\sqrt{T_{w}^{2}+D^{2}}-\sqrt{T_{\text {ref }}^{2}+D^{2}}\right) \\
& \text { Where }_{C_{\infty}}=2300 \frac{j}{k g^{\circ} \mathrm{K}}, \mathrm{D}=800^{\circ} \mathrm{K} \text { and } \mathrm{T}_{\text {ref }}=300^{\circ} \mathrm{K} .
\end{aligned}
$$

\section{NUMERICAL SOLUTION}

For solving equation (1), the governing partial differential equations are substituted by approximation of finitedifference. According to the nonlinear nature of the governing equations, Newton-Rafson method is used with TDMA algorithm to solve the algebra equation system.

Using Newton-Rafson method in solving governing equations is one of the advantages of the numerical calculation method and it can be easily generalized to more complex problems. In Newton-Rafson method, the nonlinear equation complexity is not considered, because the structural constant of the governing equation system can be obtained by differentiation relative to every independent variable and the resulted equation system is a linear equation system relative to the amount of changes of every independent variable (here $\Delta T$ ), and in addition, the most important property of the 
resulted equation system is that using TDMA algorithm, the amount of changes of every independent variable can be obtained in each iteration, and by adding the amount of changes in one variable to the previous one, the resulted variable value disappeared in the governing equation system constants, then the new equation system is again calculated by TDMA method and this method continues up to complete convergence. In general, nonlinear equation system is assumed as:

$$
\left\{\begin{array}{l}
F_{1}\left(x_{1}, x_{2}, \ldots, x_{n}\right)=0 \\
F_{2}\left(x_{1}, x_{2}, \ldots, x_{n}\right)=0 \\
\cdot \\
\cdot \\
F_{n}\left(x_{1}, x_{2}, \ldots, x_{n}\right)=0
\end{array}\right.
$$

Note that all $F_{i}$ are zero, so differential of these functions is zero and this relation can be expressed as:

$$
\left\{\begin{array}{l}
\frac{\partial F_{1}}{\partial x_{1}} \Delta x_{1}+\frac{\partial F_{1}}{\partial x_{2}} \Delta x_{2}+\ldots+\frac{\partial F_{1}}{\partial x_{n}} \Delta x_{n}+F_{1}=0 \\
\frac{\partial F_{2}}{\partial x_{1}} \Delta x_{1}+\frac{\partial F_{2}}{\partial x_{2}} \Delta x_{2}+\ldots+\frac{\partial F_{2}}{\partial x_{n}} \Delta x_{n}+F_{2}=0 \\
\cdot \\
\frac{\partial F_{n}}{\partial x_{1}} \Delta x_{1}+\frac{\partial F_{n}}{\partial x_{2}} \Delta x_{2}+\ldots+\frac{\partial F_{n}}{\partial x_{n}} \Delta x_{n}+F_{n}=0
\end{array}\right.
$$

$\Delta x_{i}$ is calculated by solving the above system and after calculating $\Delta x_{i}$ the new value of $\mathrm{x}_{\mathrm{i}}$ is specified as:

$$
x_{i}^{k+1}=x_{i}^{k}+\Delta x_{i}^{k}
$$

In above equation the superscript $(\mathrm{k}+1)$ introduces the new values and superscript $\mathrm{k}$ introduces the previous values.

The given method is a repetition until it obtains complete convergence.

\section{RESULTS}

In order to make certain that the Newton-Rafson method is accurate in solving the governing equations, first, 1-D non linear heat transfer equation is solved as follows in a condition that the material properties are a function of temperature and the results are generalized to more complex problems. In analyzing this problem, the specific heat capacity of material, and heat conductivity coefficient not only aren't considered constant but also are assumed as a function of temperature, but the material density is constant. For this problem, governing equation, initial conditions, and boundary conditions are considered as:

$$
\left\{\begin{array}{l}
\frac{\partial}{\partial z}\left(k \frac{\partial T}{\partial z}\right)=\rho C_{p} \frac{\partial T}{\partial t} \quad \text { for } 0 \leq z \leq L \\
-\left.k \frac{\partial T}{\partial z}\right|_{z=0}=\dot{q^{\prime \prime}} \\
-\left.k \frac{\partial T}{\partial z}\right|_{z=L}=0 \\
T(z, t=0)=T_{0}
\end{array}\right.
$$

Variation of heat conductivity coefficient and specific heat capacity is assumed linear according to temperature and is expressed with the following relations:

$$
\begin{aligned}
& k(T)=k_{1}+\frac{k_{2}-k_{1}}{T_{2}-T_{1}}\left(T-T_{1}\right) \\
& C_{p}(T)=C_{p, 1}+\frac{C_{p, 2}-C_{p, 1}}{T_{2}-T_{1}}\left(T-T_{1}\right) \\
& \alpha=k /\left(\rho C_{p}\right)=k_{1} /\left(\rho C_{p, 1}\right)=k_{2} /\left(\rho C_{p, 2}\right)
\end{aligned}
$$

The analytical solution of this problem is performed with the following transfer [11]:

$\theta=\frac{1}{k_{\text {ref }}} \int_{T_{\text {ref }}}^{T} k(\hat{T}) d \hat{T}$

By considering $T_{r e f}=T_{1}$ and $k_{r e f}=k_{1}$ after integrating calculation, $\theta$ is obtained as:

$\theta=\left(T-T_{1}\right)+\frac{k_{2}-k_{1}}{T_{2}-T_{1}} \frac{1}{2 k}\left(T-T_{1}\right)^{2}$

The above relation is a quadratic equation according to $\left(T-T_{1}\right)$ and after solving it the following relation is obtained:

$$
\begin{aligned}
& \left(T-T_{1}\right)= \\
& \left(T_{2}-T_{1}\right)\left(\frac{k_{1}}{k_{2}-k_{1}}\right)\left[-1 \pm \sqrt{1+\frac{2 \theta}{T_{2}-T_{1}}\left(\frac{k_{2}-k_{1}}{k_{1}}\right)}\right]
\end{aligned}
$$

By transferring the energy equation, boundary conditions and initial conditions, the following relations are obtained:

$$
\left\{\begin{array}{l}
\frac{\partial \theta}{\partial t}=\alpha \frac{\partial^{2} \theta}{\partial z^{2}} \quad \text { for } \quad 0 \leq z \leq L \\
-\left.k_{1} \frac{\partial \theta}{\partial z}\right|_{z=0}=\dot{q} \\
-\left.k_{1} \frac{\partial \theta}{\partial z}\right|_{z=L}=0 \\
\theta(z, t=0)=\theta_{0}=\theta\left(T=T_{0}\right)
\end{array}\right.
$$

Transferred energy equation is completely similar to energy equation with constant material properties.

Therefore, the solution is:

$$
\begin{aligned}
\frac{\theta(z, t)-\theta_{0}}{\dot{q}^{\prime \prime} L / k}= & \frac{\alpha t}{L^{2}}+\frac{1}{3}-\frac{z}{L}+\left(\frac{z}{L}\right)^{2}- \\
& \frac{2}{\Pi^{2}} \sum_{n=1}^{\infty} \frac{1}{n^{2}} \exp \left(-n^{2} \Pi^{2} \frac{\alpha t}{L^{2}}\right) \cos \left(n \Pi \frac{z}{L}\right)
\end{aligned}
$$


The considered parameters given in Table (1) and Table (2) for solving the problem introduce the conductivity coefficient variations and specific heat capacity relative to the temperature. In figure 2 the results of present code are compared with analytical solution results in $\mathrm{t}=4 \mathrm{~s}$ and $\mathrm{t}=40 \mathrm{~s}$. As can be seen, there is suitable conformity between the obtained results from solving equation with Newton-Rafson method and the results, obtained from analytical solution, and this matter emphasizes the accuracy of Newton-Rafson method in solving the non linear equations.

TABLE I NECESSARY PARAMETER FOR SOLVING THE NON LINEAR PROBLEMS OF ONE DIMENSIONAL TRANSIENT HEAT TRANSFER

\begin{tabular}{|c|}
\hline OF ONE DIMENSIONAL TRANSIENT HEAT TRANSFER \\
\hline$T_{0}=300 \mathrm{k}$ \\
\hline$\dot{q}=7.5 \times 10^{5} \mathrm{w} / \mathrm{m}^{2}$ \\
$L=0.01 \mathrm{~m}$ \\
$\rho=8000 \mathrm{~kg} / \mathrm{m}^{3}$ \\
\hline$\alpha=k /\left(\rho C_{p}\right)=2.5 \times 10^{-6} \mathrm{~m}^{2} / \mathrm{s}$
\end{tabular}

TABLE II VARIATIONS OF HEAT CONDUCTIVITY COEFFICIENT AND HEAT CAPACITY COEFFICIENT ACCORDING TO TEMPERATURE

\begin{tabular}{|c|c|c|}
\hline $\mathrm{T}(\mathrm{K})$ & $\mathrm{K}(\mathrm{w} / \mathrm{mk})$ & $\mathrm{C}_{\mathrm{P}}(\mathrm{J} / \mathrm{kg} \mathrm{k})$ \\
\hline 300 & 10 & 500 \\
\hline 1300 & 100 & 500 \\
\hline
\end{tabular}

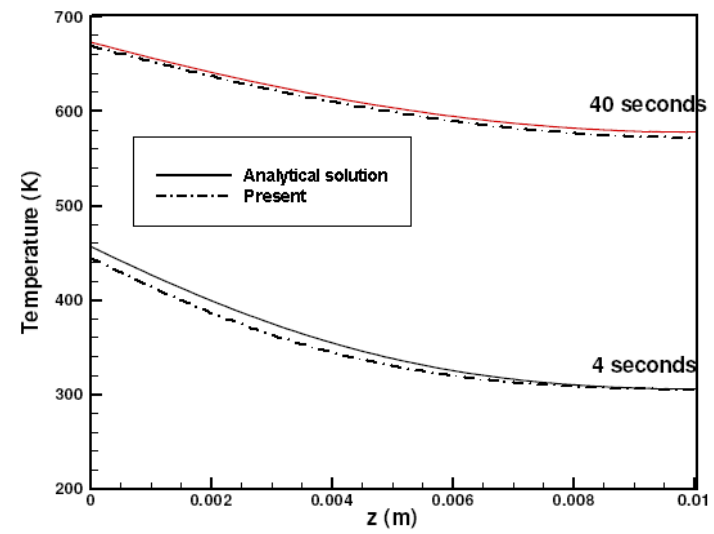

Fig. 2 comparison of temperature distribution of the present code in the times of $\mathrm{t}=4 \mathrm{~s}$ and $\mathrm{t}=40 \mathrm{~s}$ with the results from analytical solution

For determine the temperature distribution inside the charring and non-charring ablative material and For determine the final recession surface, at first, the ablative material type should be assigned. The compiling code is able to solve the governing equation on non-charring material with suitable accuracy. Using the Newton-Rafson method in solving the governing equations is one of the advantages of this code because this method is understood very easily and also it can be generalized to more complex problems easily. In order to become certain about the program accuracy the results are compare with reference [11] results.
The considered problem in this reference is a missile that enters to atmosphere with from the $90 \mathrm{~km} \mathrm{MSL}^{1}$ but the trajectory data are not specified. The cold wall heat flux, the recovery enthalpy, and the pressure of ablative material on a specific location of the missile are presented in Ref. [10].The input code includes cold wall heat flux, recovery enthalpy, and pressure. Therefore with consideration to relations, regarded to stagnation point, this quantity is calculated by data trajectory. The composite density is $1200 \mathrm{~kg} / \mathrm{m}^{3}$ and variation of heat conductivity coefficient by temperature is shown in Table 3 .

TABLE III VARIATIONS OF CARBON-CARBON COMPOSITE PROPERTIES B
\begin{tabular}{|c|c|c|}
\hline TEMPERATURE & K(w/mk $)$ & $\mathrm{C}_{\mathrm{P}}(\mathrm{J} / \mathrm{gr} \mathrm{k})$ \\
\hline 300 & 123.6 & 0.72 \\
\hline 400 & 116.5 & 0.99 \\
\hline 600 & 102.8 & 1.41 \\
\hline 800 & 90.6 & 1.65 \\
\hline 1000 & 80.4 & 1.79 \\
\hline 1200 & 71.6 & 1.89 \\
\hline 1400 & 64.9 & 1.95 \\
\hline 1600 & 59.8 & 2.04 \\
\hline 1800 & 57 & 2.07 \\
\hline 2000 & 55.1 & 2.1 \\
\hline 2200 & 53.8 & 2.13 \\
\hline 2400 & 53.1 & 2.16 \\
\hline 5000 & 50 & 2.23 \\
\hline
\end{tabular}

Figure (3) shows a comparison between obtained results and ones from reference [12]. Additionally, it is noticeable that the surface recession results are more than surface temperature distribution results. In addition, the conformity of the results of the present code with ones from finite difference (FD) method is more than the results of HBI method from reference [12]. This shows the accuracy of the present code, because HBI is an approximate method and its only advantageous aspect is high speed function and accordingly, low performance time.

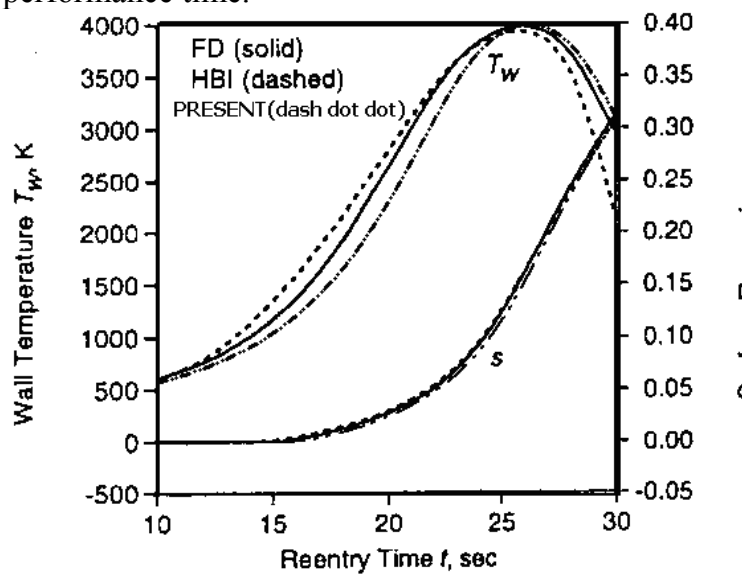

Fig. 3 comparison the profile of temperature distribution and recession surface of present code with other results.

\footnotetext{
${ }^{1}$ Mean See Level
} 


\section{CONCLUSION}

In this study the governing equations of non-charring ablative materials, including energy equation, in transient state is calculated by numerical method and the history of temperature distribution in the base metal, surface recession and pyrolisis gas flux are measured. To do so and make the energy equation linear, Newton-Rafson method is used, because in this method the complexity of nonlinear equation is not so important so the structural constants of the new linear equation system is obtained by differentiation relative to every independent variable. Also the most important feature of this equation system is that by using TDMA algorithm we can obtain the amount of changes of every independent variable in each iteration and by adding the amount of changes of each variable to the previous value the new variable value is appeared in the governing equation system constants and this method continues up to complete convergence. Using Newton-Rafson method in solving the governing equations is one of the advantages of the presented code. Because this method is easy to understand and can be easily generalized to more complex problems. Besides, this method has a suitable accuracy in solving nonlinear equations because despite the dispersion and low amount of input data, there's a good conformity between the presented results and the results from other references.

\section{REFERENCES}

[1] S.R. Candane, C.Balaji, and S.P.Venkateshan, A Comparison of Quasi one-Dimensional and two-dimensional Ablation Models for Subliming Ablators, International Journal of Heat transfer engineering, 30(3):229236, 2009.

[2] A. Mazzaracchio, M. Marchetti, A probabilistic sizing tool and Monte Carlo analysis for entry vehicle ablative thermal protection systems, Acta Astronautica,2009.

[3] J. D. Anderson, Hypersonic and high temperature gas dynamics. McGraw-Hill,1989.

[4] A.J Amar Modeling of One-dimensional Ablation With Porous Flow Using Finite Control Volume Procedure, requirements for the Degree of Master of Science. Raleigh 2006.

[5] J. Lachaud, Y. Aspa, G.L. Vignoles, International Journal of Heat and Mass Transfer 51(9-10) 2618-2627, 2008.

[6] E.Fitzer, L.M Manocha, Carbon Reinforcements and C/C composites, Springer, p. 342. 1998.

[7] G.duffa, G.L.vignoles, J.M. Goyheneche, Y.Aspa, International Journal of Heat and Mass transfer 48(16):3387-3401, 2005.

[8] H. Hurwics., Aerothermochemistry studies in Ablation ., Thermo dynamics Analysis section, Research and Advanced Development Division. Avco Corporation, Wilmington, Massachusetts, 1963.

[9] G. W. Russell, Analytic Modeling and Experimental validation of In tumescent Behavior of Charring Heat shield Materials‘ Technical Report AMR-PS-04-05, January 2004.

[10] R. L. Potts., Application of Integral Methods to Ablation Charring Erosion, AIAA/ASME Thermo physics and Heat Transfer Conference, June 1990.

[11] V. S. Arpaci, Conduction Heat Transfer, Addison-Wesely, Reading, MA, 1966.

[12] R. M. Kendall, E. P. Bartlett, R. A. Rindal and C. B. Moyer, An Analysis of The Coupled Chemically Reacting Boundary Layer and Charring Ablator, Part 1, June,NASA CR-1060,1968. 